\title{
Improving Legibility of Motor Current Spectrum for Broken Rotor Bars Fault Diagnostics
}

\author{
Bilal Asad* (Ph. D. Student, Tallinn University of Technology, Tallinn, Estonia), \\ Toomas Vaimann (Senior Researcher, Tallinn University of Technology, Tallinn, Estonia), \\ Ants Kallaste (Researcher, Tallinn University of Technology, Tallinn, Estonia), \\ Anton Rassõlkin (Senior Researcher, Tallinn University of Technology, Tallinn, Estonia), \\ Anouar Belahcen (Professor, Aalto University, Espoo, Finland), \\ M. Naveed Iqbal (Ph. D. Student, Tallinn University of Technology, Tallinn, Estonia)
}

\begin{abstract}
In this paper, the harmonic contribution of the broken rotor bar of an induction machine is investigated using an effective combination of the fast Fourier transform (FFT) and a band stop filter. The winding, spatial, grid fed and fault-based harmonics are investigated. Since the fundamental component is the most powerful component as compared to the other frequencies, it decreases the legibility of spectrum, making logarithmic scale inevitable. It also remains a potential threat of burying the fault representative side band frequencies because of its spectral leakage. In this paper, a band stop Chebyshev filter is used to attenuate the fundamental component, which makes the spectrum clearer and easier to understand even on the linear scale. Its good transition band and low passband ripples make it suitable for attenuating the main supply frequency with low impact on the neighbouring side band frequencies. To study the impact of fault on magnetic flux distribution, simulation is done using finite element method with good number of mesh elements and very small step size. The line current is calculated and frequency spectrum is investigated to segregate the spatial and fault frequencies using the proposed technique. The results are further validated by implementing the algorithm on the data measured in the laboratory environment including the grid fed harmonics.
\end{abstract}

Keywords - Digital filters; Fault diagnosis; Fourier transform; Induction motors.

\section{INTRODUCTION}

From the start of the second industrial revolution, induction motors have become the key element of modern-day industry due to variety of their applications ranging from generation to consumer domains. In the form of doubly fed induction generators, they make an integral part of renewable energy resources, such as wind power plants, and in the form electrical to mechanical energy converters, they are driving the cycle of industry making an impact on a nation's economy. They are also being extensively used in commercial and domestic applications, such as electric vehicles, fans, water pumps, etc. There are many machines that can convert electrical energy to mechanical energy, but simple structure, good efficiency and ease of maintenance of induction motors have made them the most common among all. They are the biggest consumer of electricity, consuming about $50 \%$ of the total generated energy worldwide [1].

These machines always remain vulnerable to faults because they contain mechanically moving parts. These faults can be broadly classified into electrical and mechanical. Electrical faults are mainly associated with the stator, such as voltage imbalance, phase drop, inter-turn short circuits and earthing faults, etc. Mechanical faults make the biggest proportion of overall faults, such as damaged bearings, broken rotor bars, broken end rings and eccentricity faults, etc.

These faults are directly or indirectly related with each other and are degenerative in nature. Hence, it is very important to detect them at an incipient stage in order to avoid extensive economic loss and time-consuming repair processes.

Fig. 1 shows both the energy consumed by induction motors as a percentage of the total used energy and a comparative difference between recondition and rewind costs of different power induction motors as proposed by Penrose in [2]. Due to the above-mentioned facts, the field of fault diagnostics is becoming as important as the field of machine design and control.

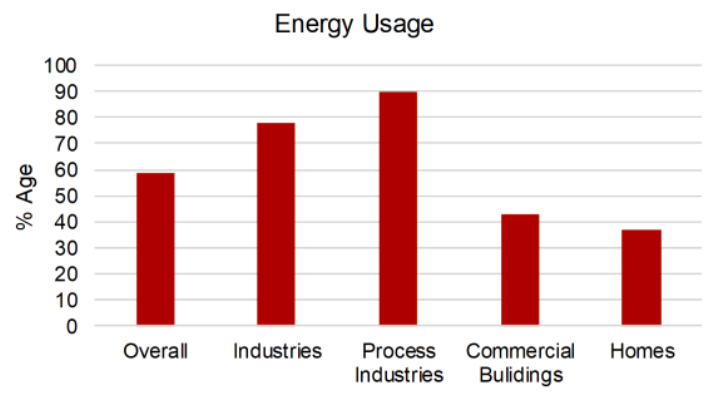

(a)

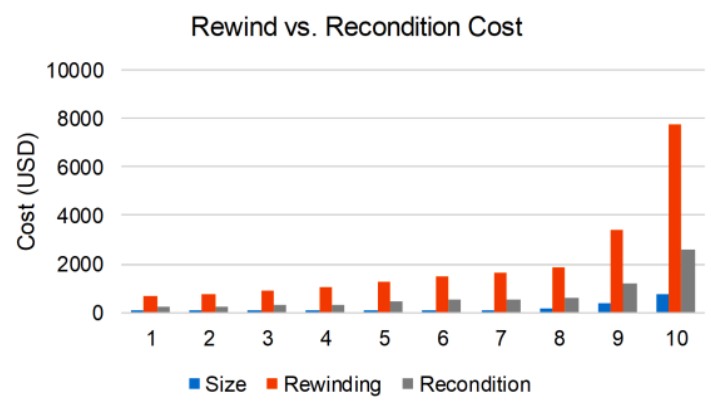

(b)

Fig. 1. Worldwide energy usage by electrical machines (a), and a comparison of rewind vs. recondition costs (b).

\footnotetext{
* Corresponding author.

E-mail: biasad@ttu.ee

(C)2019 Bilal Asad, Toomas Vaimann, Anton Rassõlkin, Ants Kallaste, Anouar Belahcen, M. Naveed Iqbal.

This is an open access article licensed under the Creative Commons Attribution License
}

(http://creativecommons.org/licenses/by/4.0), in the manner agreed with Sciendo. 
Motor current signature analysis (MCSA) based fault diagnostic techniques are extensively used in research, because these techniques are mostly non-invasive in nature and require simple measurements. After the current measurement, an entire domain of signal processing techniques may be used to estimate the nature and the severity of the fault.

Fourier series has laid the foundation for almost all kinds of modern signal processing techniques. The majority of signal processing-based fault diagnostic techniques depend on Fourier analysis due to the need to investigate the frequency spectrum. This is so, because every kind of fault leaves some specific harmonics in the frequency spectrum of the stator current. The majority of MCSA based techniques depend on the fast Fourier transform (FFT) of the signal, e.g. in [3], the authors used the FFT on active and reactive currents of a motor to investigate the broken rotor bars and load oscillations. The authors of [4] used the FFT in conjunction with Park's vector to develop artificial ants clustering technique for the fault diagnostics of induction motor. In [5], the autoregressive method relies on discrete time Fourier transform (DTFT) and notch filter. Researchers in [6] used the FFT to prove that the slot harmonics can be used as potential indicators to detect the broken rotor bars. In [7], the authors used an adaptive notch filter and FFT for broken rotor bar fault diagnostics of the induction motor. The authors of [8] used the FFT to analyse simulations and practical results to investigate the broken rotor bars and mechanical vibrations. In [9], Nandi used the FFT extensively to study the frequency spectrum of the stator current for different fault conditions. [10] used the FFT along with the band stop filter for detection of broken rotor bar frequencies.

The spectral leakage of the fundamental component is the most profound problem associated with the FFT. The fundamental component contains more power than the other higher order harmonics, such as the spatial and the fault baring harmonics. Therefore, the logarithmic scale is usually preferred for better legibility of the spectrum, but spectral leakage remains and is likely to hide the frequency components near the fundamental component. In addition, at low slip conditions, spectral leakage problem becomes severe, because in case of most of the rotor-associated faults the frequencies depend on the slip. Some techniques can be found in literature, in which the researchers have tried to reduce the problem of the spectral leakage. The authors of [11] have used the Hilbert transform to get the envelope of the signal containing potential information about the faults. The authors in [12] used the fractional Fourier transform to recover the faulty frequencies from a non-stationary signal. In [13], the authors used the sliding discrete Fourier transform for detection of broken rotor bars. [14], [15], [16] used wavelet technique to improve the accuracy, but it led to complexity of algorithm.

In this paper, the Chebyshev filter is used due to its better brick wall characteristics compared to other filters, such as Butterworth, Hilbert, etc. In contrast to most of the papers, which focus mainly on the frequency spectrum containing faulty frequency harmonics on the logarithmic scale, while neglecting the supply fed harmonics, in this paper the entire frequency spectrum on the linear scale is studied, using the motor currents taken from both finite element-based simulations and experiments. Moreover, the grid fed harmonics are also tracked to make the picture clearer. It is shown that the proposed filter makes the spectrum much more legible and effectively removes the fundamental component without disturbing all other harmonics.

\section{MATHEMATICAL BACKGROUND}

\section{A. Slots and Broken Bar Harmonics}

In case of a healthy motor, the frequency spectrum of the stator and rotor current contains a number of harmonics because of the distributed nature of rotor and stator windings, even if the supply is taken as ideal. These harmonics can be represented with the help of stator current linkage and the winding factor by the following equation [1]:

$$
\begin{gathered}
M M F(t, \alpha)=\frac{3}{\pi}\left(\frac{k_{\mathrm{wf}} N_{\mathrm{s}}}{v p}\right)\left(I \mathrm{e}^{\mathrm{j}(\omega t-v \alpha)}\right), \\
k_{\mathrm{wf}}=\frac{\sin \frac{n \pi}{2}}{N} \sum_{\rho=1}^{N} \cos \propto_{p},
\end{gathered}
$$

where $N_{\mathrm{s}}$ is the number of conductors per phase, $k_{\mathrm{wf}}$ is the winding factor, $p$ is the number of pole pairs, $v$ is the harmonic number, $N$ is the total number of slots and $\alpha$ is the angle of the corresponding slot.

Every fault modulates the stator current with a specific frequency and modulation index, depending on the severity of the fault. These fault frequencies can be described mathematically as a function of the geometrical and electrical parameters of the rotor and stator. Extensive mathematics representing these faults can be found in [9], [11]-[19] and the simplified version - in [20]. The detection of the broken bar at an incipient stage is necessary, because when one bar breaks, its consecutive bars come under more thermal stress that leads to their breakage. These faults produce the following harmonics in the frequency spectrum [21]:

$$
\begin{gathered}
f_{\mathrm{BR}}=f_{\mathrm{s}} \pm 2 k s f_{\mathrm{s}} \\
f_{\mathrm{BR}}=\left[\left(\frac{k}{p}\right)(1-s) \pm s\right] f_{\mathrm{s}}
\end{gathered}
$$

where $k=1,2,3, \ldots, f_{\mathrm{s}}$ is the supply frequency, $p$ is the number of pole pairs and $s$ is the slip of the machine. The lower sideband appears due to the broken rotor bar and the upper sideband due to the resultant speed oscillations. The dependency of these harmonic frequencies on the slip makes them more likely to be buried under the spectrum of the fundamental component. This problem becomes most severe under small and no-load conditions. In addition, the amplitude of these frequencies depends on the number of broken bars and is relatively small compared to the amplitude of the supply frequency.

\section{B. Fourier Transform}

The FFT is used in almost every field of science, as it provides the possibility to segregate a non-periodic random signal into sinusoids having specific frequency and amplitude called the harmonics. The amplitude of these harmonics usually attenuates as they travel along the frequency axis, making the fundamental component the most significant one. The discrete Fourier transform (DFT) and its inverse can be represented by the following formulas: 


$$
\begin{gathered}
X_{k}=\sum_{n=0}^{N-1} x_{n} \mathrm{e}^{-i 2 \pi k n / N}, \quad k=0,1,2, \ldots,(N-1) ; \\
x_{n}=\frac{1}{N} \sum_{n=0}^{N-1} X_{n} \mathrm{e}^{-i 2 \pi k n / N}, \quad k=0,1,2, \ldots,(N-1),
\end{gathered}
$$

where $N$ is the number of samples, $n$ is the current sample, $x_{n}$ is the value of the signal at time $n, k$ is the current frequency and $X_{k}$ is the resultant bin of the DFT. Frequency resolution is very important for a complete and accurate frequency spectrum, which depends upon the measurement time of the signal and the sampling frequency, as shown in the following equation:

$$
\Delta f=1 / T_{m}=f_{\mathrm{s}} /_{N}=B W / S L=2 \cdot B W / N,
$$

where $\Delta f$ is the frequency difference between two consecutive frequency bins, $N$ is the number of samples, $B W$ is the bandwidth and $S L$ is the number of spectral lines.

Since the taken signal is of a finite length and the length of the signal may not be an integer multiple of all frequency components, this will lead to a problem of spectral leakage. Being the most significant component, fundamental component can have a larger tendency of spectral leakage, amplifying the need of an attenuation filter.

\section{Chebyshev Filters}

Digital filters are mathematical algorithms, which are capable to reduce or enhance certain parameters of a signal. Because of their diversified nature, they may be of many types and are extensively used in almost every signal processing-based application.

The Chebyshev filters are well known for their better step response as compared to the Butterworth filter. Its gain response as a function of frequency $\omega$ can be represented as:

$$
G_{n}(\omega)=1 / \sqrt{1+\varepsilon^{2} T_{n}^{2}\left(\omega / \omega_{\mathrm{o}}\right)},
$$

where $\varepsilon$ is ripple factor, $\omega_{\mathrm{o}}$ is cutoff frequency and $T_{n}$ is its polynomial of $n^{\text {th }}$ order.

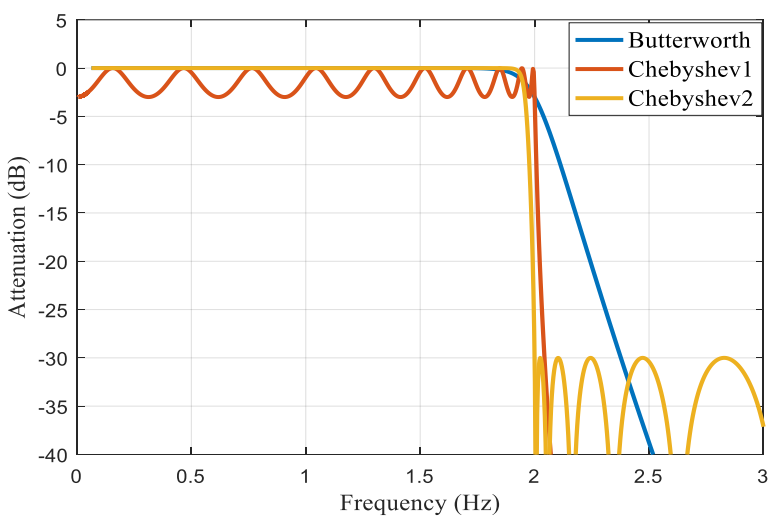

Fig. 2. Step response of the Butterworth and Chebyshev filters

Fig. 2 shows a comparative analysis of the Butterworth and Chebyshev type I and type II filters for the same tuning parameters. It is evident that the Butterworth filter is flat in its passband interval but has a bad roll-off, which can be fatal for fault frequencies lying very close to the fundamental component in case of a broken rotor bar. The Chebyshev filters have a very good transition band but have ripples in the passband in case of type I, and stopband in case of type II.

\section{Finite Element Method for Motor Simulation}

The mathematical modelling and simulations of induction motors are extremely important, as they provide the basis for design and control procedures. The more accurate the mathematical model of the machine is, the more accurate its practical design and control would be. The analytical method is the most common method of modelling found in literature. This method consists in describing the system with the help of integra-differential equations. Analytical models usually neglect the complex nonlinear behaviour of the system to make it simpler. With the increase in computational power, the numerical models such as FEM are gaining more popularity in the field of modelling and simulations. These models are good approximations of an actual system, as they consider all possible parameters, but at the cost of complexity and long computational time. The numerical model of the induction motor relies on the Maxwell's equations:

$$
\begin{gathered}
\nabla \times E=-\frac{\partial B}{\partial t} ; \\
\nabla \times H=J+\frac{\partial D}{\partial t} ; \\
H=v B ; \\
J=\sigma E,
\end{gathered}
$$

where $E$ is the electric field strength, $B$ is the magnetic flux density, $D$ is displacement current, $D$ is electric flux density, $H$ is the magnetic field strength, $J$ is the current density, $v$ is the magnetic reluctivity of material and $\sigma$ is its electric conductivity.

By assuming that the magnetic field lies in an $x-y$ plane, varies sinusoidally in time and induces currents in the $z$ direction, the vector potential A distributes in the machine according to the following equation [22]:

$$
\frac{\partial}{\partial x}\left(\frac{1}{\mu}\right) \frac{\partial A}{\partial x}+\frac{\partial}{\partial y}\left(\frac{1}{\mu}\right) \frac{\partial A}{\partial y}-s \frac{\partial}{\partial t}(\sigma A)+J=0 .
$$

If the conductivity of the rotor and stator laminations is taken as zero, and the reluctivity of conducting regions as that of the vacuum, the electric scalar potential and voltage equation of a conductor can be represented as [8]:

$$
\begin{gathered}
\nabla \varphi=-\frac{u}{l} e_{z}, \\
u=i R+R \oint \sigma \frac{\partial A_{z}}{\partial t} \cdot d s .
\end{gathered}
$$

\section{SIMULATION RESULTS AND DISCUSSION}

The FEM-based simulation of a three-phase induction motor with the parameters shown in Table I is performed under healthy, one, and two broken rotor bar conditions. Since the simulation is performed using 2D field analysis, the ignored end windings are compensated by adding additional resistances and inductances in the series with coils. The per phase stator coils 
are series and parallel connections of copper strands making current density uniformly distributed.
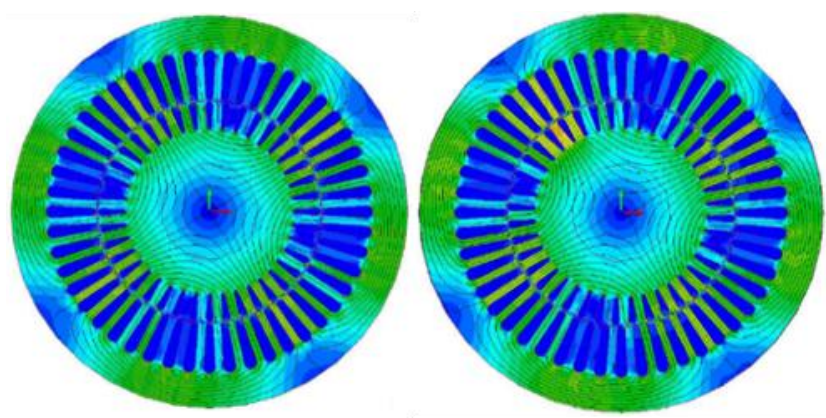

Fig. 3. Normalized magnetic field density of healthy and broken rotor bar motors.

The simulation is performed at rated load under constant speed. The flux distribution under healthy and two broken rotor bar conditions is shown in Fig. 3. It is evident that the flux density increases across broken bars, putting the adjacent bars under increased magnetic stress. The increase in the current of the neighbouring bars makes the machine vulnerable to breakage of more bars in time, if the fault is not timely diagnosed and repaired.

Fig. 4 shows the motor simulation results for stator currents and frequency spectrum under healthy and broken rotor bar conditions from top to bottom. In the first graph, zoomed stator current is shown, which is calculated using a step size of $0.033 \mathrm{~ms}$ at the rated load condition using FEM. The simulation is performed for two seconds with 5328 mesh elements at stator and rotor temperatures of $120^{\circ} \mathrm{C}$ and $140{ }^{\circ} \mathrm{C}$, respectively. The current seems distorted because of time and slot harmonics. The second graph represents the positive side of the current and its envelope under two broken bar condition.

The envelope clearly represents the effect of the broken rotor bars and the modulation of the motor current. The ripples in the envelope of the current increase with the increase in the
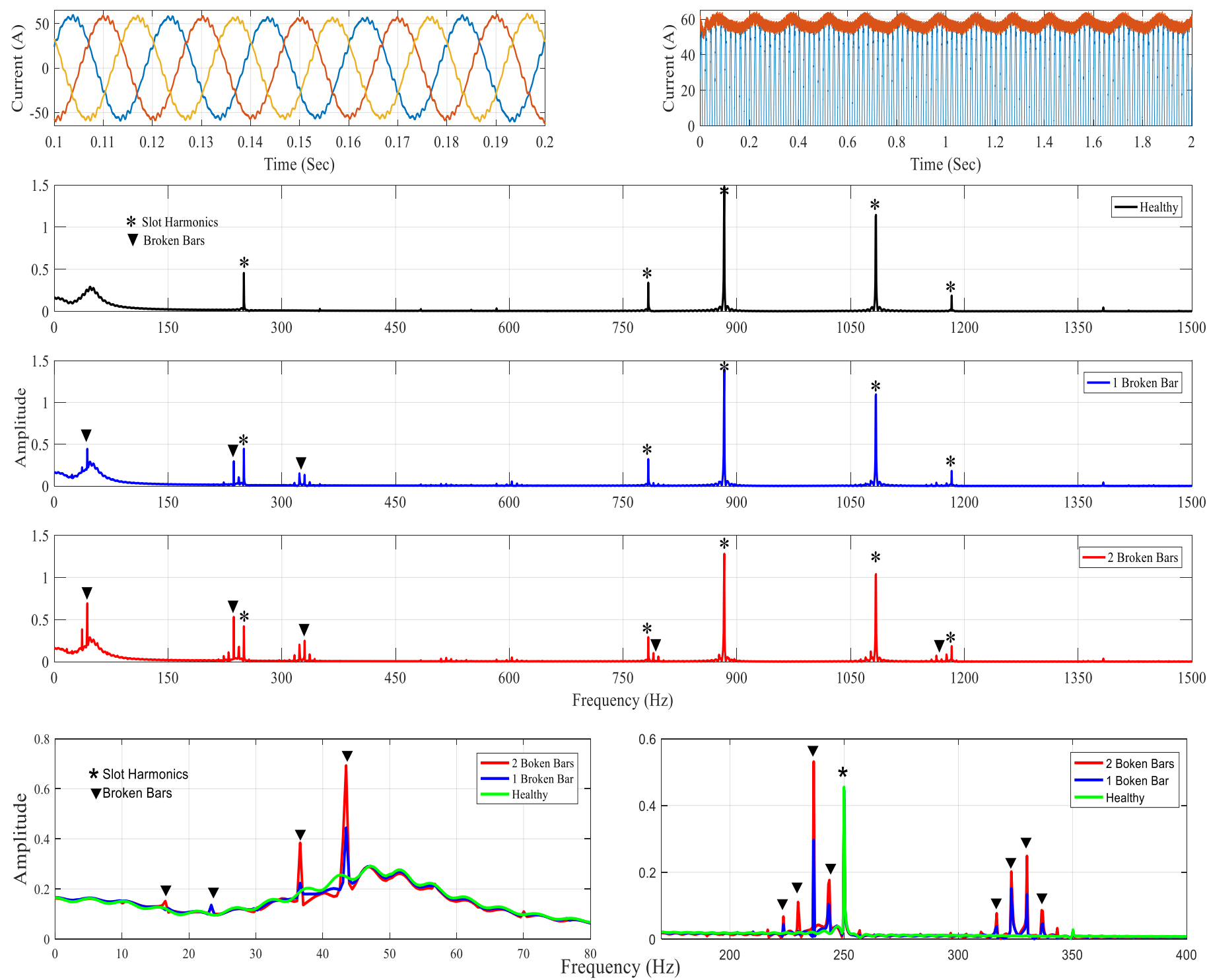

Fig. 4. Simulation results; three phase current in top left, per phase current and its envelope for three broken bars in top right, frequency spectrum for healthy, 1 broken and 2 broken bar cases from top to down; zoomed comparison of harmonics for healthy and faulty motors in bottom two graphs. 
2019, vol. 15 , no. 1

modulation index, which depends on the number of broken bars. The distribution of the harmonics in the frequency spectrum of the stator current is shown in the next three graphs for healthy, one broken bar, and two broken bar cases, respectively. The fundamental component of the supply voltage is attenuated, making the spectrum legible on the linear axis. The frequency components can be easily differentiated due to the spatial and broken rotor bar harmonics. In the last two graphs, the frequency spectrums in the range of $0-80 \mathrm{~Hz}$ and $170-400 \mathrm{~Hz}$ are plotted on the same window for healthy and faulty cases for a comparative analysis. It is clear that the faulty frequencies increase in amplitude with the increase in the number of broken bars.

\section{EXPERIMENTAL SETUP}

The measurement setup consists of two same type motors with the parameters shown in Table I. One machine is under investigation and the other one is acting as load. Both machines are mounted on the same mechanical base and coupled through their shafts, as shown in Fig. 5(a). The loading machine is fed through the inverters to improve its controllability for various load levels and the machine under investigation is fed by grid supply containing some harmonics as discussed in results section. The stator currents and voltages are measured using the Dewetron transient recorder. The sampling frequency of the measured signals is 10000 samples per second and the measurement time is 70 seconds, giving a very good resolution of the frequency spectrum. Fig. 5(b) shows the block diagram of the test setup.

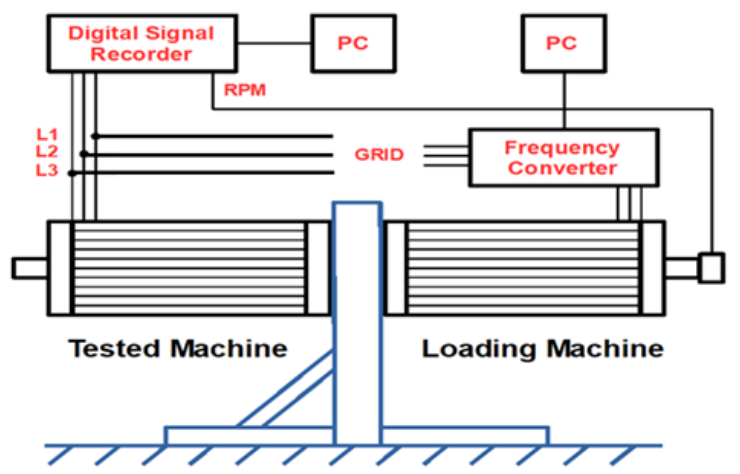

Mechanical Support Fastened to the Base

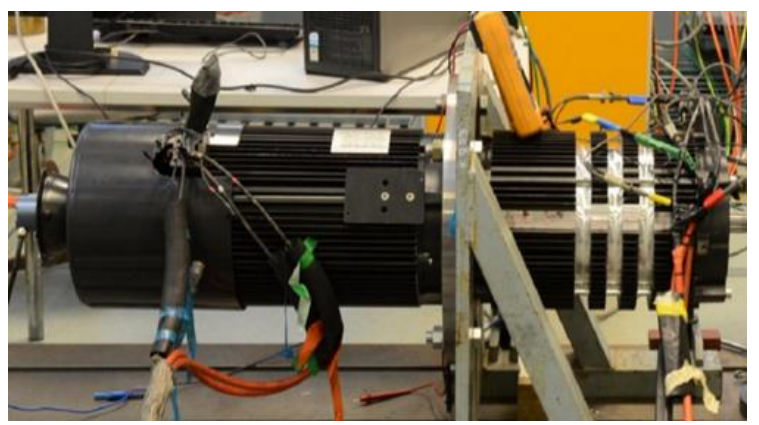

Fig. 5. (a) Experimental setup; (b) Schematic of the experimental setup.
TABLE I

MOTOR PARAMETERS

\begin{tabular}{|l|c|l|}
\hline \multicolumn{1}{|c|}{ Parameter } & Symbol & \multicolumn{1}{c|}{ Value } \\
\hline Number of poles & $P$ & 4 \\
\hline Number of phases & $\varphi$ & 3 \\
\hline Connection & $\mathrm{Y}-\Delta$ & Star \\
\hline Stator slots & $N_{\mathrm{s}}$ & $48 ;$ non-skewed \\
\hline Rotor slots & $N_{\mathrm{r}}$ & $40 ;$ non-skewed \\
\hline Terminal voltage & $V$ & $333 \mathrm{~V} \mathrm{@} 50 \mathrm{~Hz}$ \\
\hline Rated slip & $S$ & 0.0667 \\
\hline Rated power & $P_{\mathrm{r}}$ & $18 \mathrm{~kW} @ 50 \mathrm{~Hz}$ \\
\hline
\end{tabular}

\section{RESULTS AND DISCUSSION}

Fig. 6 shows the cycles of the input phase voltage and the corresponding spectrum. For better visibility of the grid fed harmonics, the fundamental component is attenuated using the proposed filter which removes it effectively without having any influence on the rest of the harmonics.
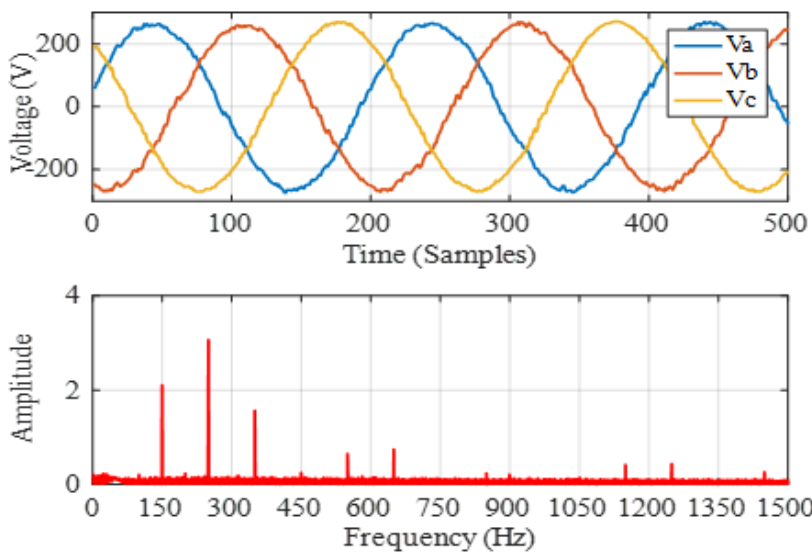

Fig. 6. Grid fed voltage and respective frequency spectrum.

The supply harmonics are mainly odd harmonics and can be represented by the following equation:

$$
f_{\mathrm{SH}}=k f_{\mathrm{s}}, \quad k=1,3,5, \ldots
$$

Fig. 7 presents the experimental results. The top two graphs represent the stator three-phase and single-phase currents. The envelope of current is also represented using the Hilbert transform to show the impact of the broken rotor bars. The current is smoother than the current taken from simulation, because the skewness of rotor bars has suppressed the slot harmonics considerably. The next graphs show the frequency spectra for healthy, one, two, and three broken bars, respectively. The fundamental component has been attenuated successfully, making the harmonics discoverable without using the logarithmic scale. It is evident in the results that under healthy condition the only prominent harmonics are supply harmonics, which will be many in case of inverter fed machines. These harmonics can be a misleading factor in diagnostic algorithms if not addressed properly. The last two graphs provide a comparative analysis of all four cases in the same window, 
2019, vol. 15, no. 1
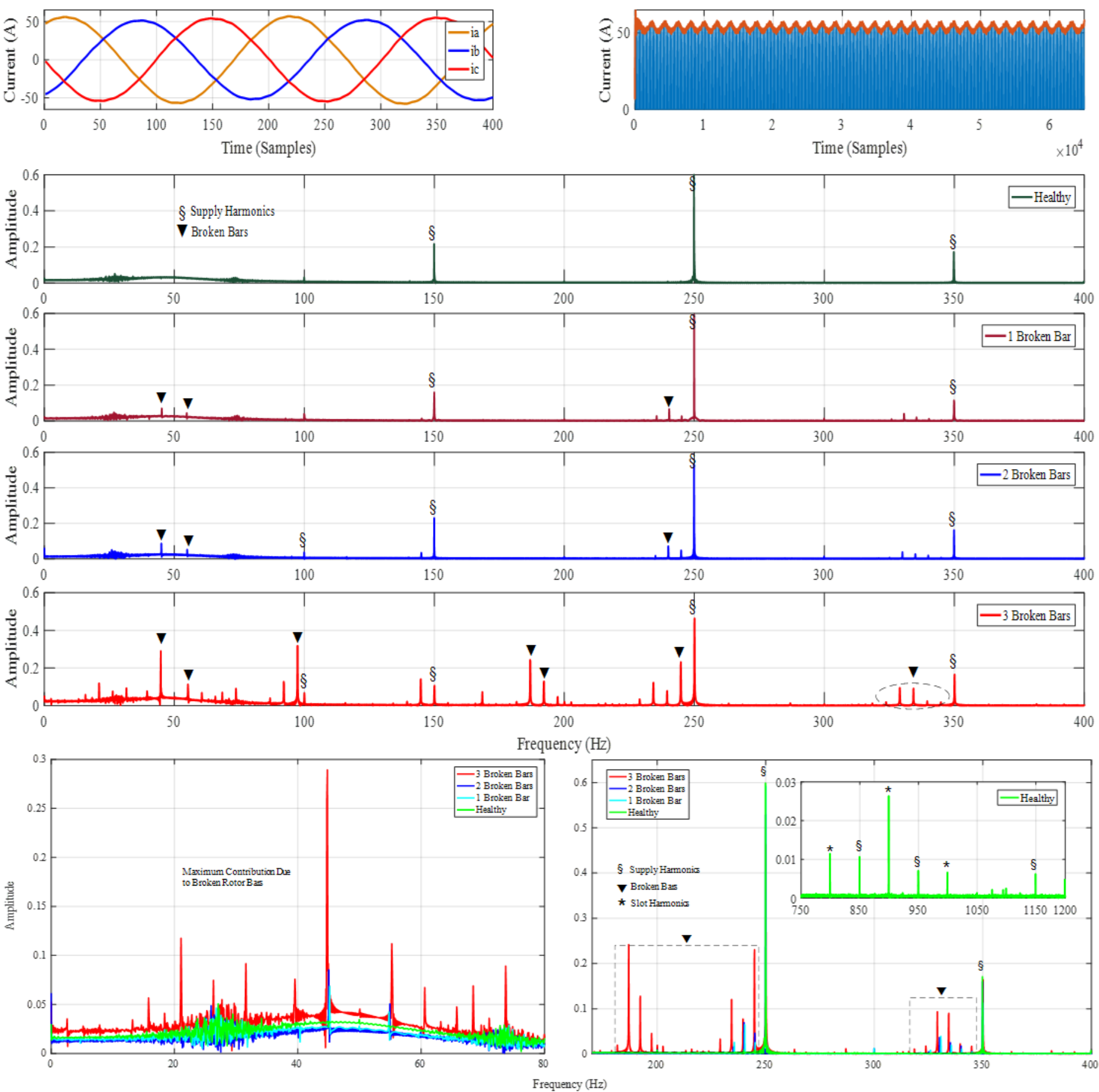

Fig. 7. Experimental results: three phase current - top left, per phase current and its envelope for three broken bars - top right, frequency spectrum for healthly, one, two, and three broken bars cases from top down; zoomed comparison of harmonics for healthy and faulty motors at the bottom.

where it can be seen that the amplitude of the fault harmonics is increasing with the increase in the number of broken bars.

\section{CONCLUSIONS}

The MCSA is the most common technique used for fault diagnostics of induction motors, due to its simplicity and noninvasive nature. In this paper, harmonic spectrum of an induction motor for healthy and broken rotor bar cases using signals from the simulation and experiments has been studied.
The FEM based simulations reveal that the rotor bars next to the broken one come under more magnetic and thermal stress making them vulnerable to breakage, increasing the severity of fault with the passage of time. Hence, it is very important for diagnostic algorithm to be able to detect the fault at the incipient stage. The accurate attenuation of the fundamental component can lead to very accurate results.

The use of the Chebyshev filter for the attenuation of the fundamental component reduces its spectral leakage 
considerably. This filter has a good transition band and makes less impact on the upper and lower sidebands of the broken rotor bar frequencies. Also, the fewer pass band ripples in case of type II filter reduce the impact of filter on the frequency spectrum.

Since the most powerful component is filtered out, it improves the legibility of the spectrum even at the linear scale. From the simulation results, the broken rotor bar and high frequency slot harmonics are easily readable on the same graph. In case of the experimental setup, since the load motor is supplied from an inverter, hence the slip of test motor is carefully controlled to investigate the location of fault frequencies.

The supply harmonics should be treated carefully, particularly in case of inverter fed machines in order to avoid false fault indications. It can be noticed that the slot harmonics are considerably suppressed by the skewing factor of the rotor.

\section{REFERENCES}

[1] J. Pyrhönen, T. Jokinen, and V. Hrabovcová, Design of rotating electrical machines. John Wiley \& Sons, Inc., Witshire, 2008.

[2] H. W. Penrose, "Test Methods for Determining the Impact of Motor Condition on Motor Efficiency and Reliability," PhD Diss., vol. ALLTEST P, no. LLC, Old Saybrook, CT, pp. 1-8.

[3] G. R. Bossio, C. H. De Angelo, J. M. Bossio, C. M. Pezzani, and G. O Garcia, "Separating Broken Rotor Bars and Load Oscillations on IM Faul Diagnosis Through the Instantaneous Active and Reactive Currents," IEEE Trans. Ind. Electron., vol. 56, no. 11, pp. 4571-4580, Nov. 2009. https://doi.org/10.1109/TIE.2009.2024656

[4] A. Soualhi, G. Clerc, and H. Razik, "Detection and Diagnosis of Faults in Induction Motor Using an Improved Artificial Ant Clustering Technique," IEEE Trans. Ind. Electron., vol. 60, no. 9, pp. 4053-4062, Sep. 2013. https://doi.org/10.1109/TIE.2012.2230598

[5] B. Ayhan, H. J. Trussell, Mo-Yuen Chow, and Myung-Hyun Song, "On the Use of a Lower Sampling Rate for Broken Rotor Bar Detection With DTFT and AR-Based Spectrum Methods," IEEE Trans. Ind. Electron., vol. 55, no. 3, pp. 1421-1434, Mar. 2008. https://doi.org/10.1109/TIE.2007.896522

[6] A. Khezzar, M. Y. Kaikaa, M. El Kamel Oumaamar, M. Boucherma, and H. Razik, "On the Use of Slot Harmonics as a Potential Indicator of Rotor Bar Breakage in the Induction Machine," IEEE Trans. Ind. Electron., vol. 56, no. 11, pp. 4592-4605, Nov. 2009. https://doi.org/10.1109/TIE.2009.2030819

[7] M. Malekpour, B. T. Phung, and E. Ambikairajah, "Stator current envelope extraction for analysis of broken rotor bar in induction motors," in 2017 IEEE 11th International Symposium on Diagnostics for Electrical Machines, Power Electronics and Drives (SDEMPED), 2017, pp. 240-246. https://doi.org/10.1109/DEMPED.2017.8062362

[8] A. Belahcen, J. Martinez, and T. Vaimann, "Comprehensive computations of the response of faulty cage induction machines," in 2014 International Conference on Electrical Machines (ICEM), 2014, pp. 1510-1515. https://doi.org/10.1109/ICELMACH.2014.6960382

[9] S. Nandi, H. A. Toliyat, and X. Li, "Condition Monitoring and Fault Diagnosis of Electrical Motors-A Review," IEEE Trans. Energy Convers., vol. 20, no. 4, pp. 719-729, Dec. 2005. https://doi.org/10.1109/TEC.2005.847955

[10] B. Asad, T. Vaimann, A. Kallaste, and A. Belahcen, "Harmonic Spectrum Analysis of Induction Motor With Broken Rotor Bar Fault," in 2018 IEEE 59th International Scientific Conference on Power and Electrical Engineering of Riga Technical University (RTUCON), 2018, pp. 1-7. https://doi.org/10.1109/RTUCON.2018.8659842

[11] R. Puche-Panadero, M. Pineda-Sanchez, M. Riera-Guasp, J. Roger-Folch, E. Hurtado-Perez, and J. Perez-Cruz, "Improved Resolution of the MCSA Method Via Hilbert Transform, Enabling the Diagnosis of Rotor Asymmetries at Very Low Slip," IEEE Trans. Energy Convers., vol. 24, no. 1, pp. 52-59, Mar. 2009. https://doi.org/10.1109/TEC.2008.2003207

[12] M. Pineda-Sanchez, M. Riera-Guasp, J. A. Antonino-Daviu, J. RogerFolch, J. Perez-Cruz, and R. Puche-Panadero, "Diagnosis of Induction Motor Faults in the Fractional Fourier Domain," IEEE Trans. Instrum. Meas., vol. 59, no. 8, pp. 2065-2075, Aug. 2010. https://doi.org/10.1109/TIM.2009.2031835
[13] M. A. Moussa, M. Boucherma, and A. Khezzar, "A Detection Method for Induction Motor Bar Fault Using Sidelobes Leakage Phenomenon of the Sliding Discrete Fourier Transform," IEEE Trans. Power Electron., vol. 32, no. 7, pp. 5560-5572, Jul. 2017. https://doi.org/10.1109/TPEL.2016.2605821

[14] S. H. Kia, H. Henao, and G.-A. Capolino, "Diagnosis of Broken-Bar Fault in Induction Machines Using Discrete Wavelet Transform Without Slip Estimation," IEEE Trans. Ind. Appl., vol. 45, no. 4, pp. 1395-1404, Jul. 2009. https://doi.org/10.1109/TIA.2009.2018975

[15] S. Singh and N. Kumar, "Detection of Bearing Faults in Mechanical Systems Using Stator Current Monitoring," IEEE Trans. Ind. Informatics, vol. 13, no. 3, pp. 1341-1349, Jun. 2017. https://doi.org/10.1109/TII.2016.2641470

[16] M. Kang and J.-M. Kim, "Reliable Fault Diagnosis of Multiple Induction Motor Defects Using a 2-D Representation of Shannon Wavelets," IEEE Trans. Magn., vol. 50, no. 10, pp. 1-13, Oct. 2014 https://doi.org/10.1109/TMAG.2014.2316474

[17] J. R. Cameron, W. T. Thomson, and A. B. Dow, "Vibration and current monitoring for detecting airgap eccentricity in large induction motors," IEE Proc. B Electr. Power Appl., vol. 133, no. 3, p. 155, 1986. https://doi.org/10.1049/ip-b.1986.0022

[18] R. R. Schoen and T. G. Habetler, "Effects of time-varying loads on rotor fault detection in induction machines," IEEE Trans. Ind. Appl., vol. 31, no. 4, pp. 900-906, 1995. https://doi.org/10.1109/28.395302

[19] H. Henao, C. Demian, and G.-A. Capolino, "A frequency-domain detection of stator winding faults in induction machines using an external flux sensor," IEEE Trans. Ind. Appl., vol. 39, no. 5, pp. 1272-1279, Sep. 2003. https://doi.org/10.1109/TIA.2003.816531

[20] A. Sapena-Bano, J. Burriel-Valencia, M. Pineda-Sanchez, R. PuchePanadero, and M. Riera-Guasp, "The Harmonic Order Tracking Analysis Method for the Fault Diagnosis in Induction Motors Under Time-Varying Conditions," IEEE Trans. Energy Convers., vol. 32, no. 1, pp. 244-256, Mar. 2017. https://doi.org/10.1109/TEC.2016.2626008

[21] J. Milimonfared, H. M. Kelk, S. Nandi, A. D. Minassians, and H. A. Toliyat, "A novel approach for broken-rotor-bar detection in cage induction motors," IEEE Trans. Ind. Appl., vol. 35, no. 5, pp. 1000-1006, 1999. https://doi.org/10.1109/28.793359

[22] N. M. Elkasabgy, A. R. Eastham, and G. E. Dawson, "Detection of broken bars in the cage rotor on an induction machine," IEEE Trans. Ind. Appl., vol. 28, no. 1, pp. 165-171, 1992. https://doi.org/10.1109/28.120226

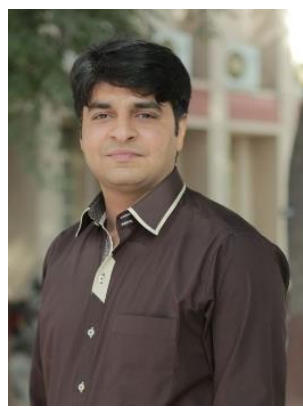

Bilal Asad was born in 1986 in Pakistan. He received his B.Sc. in Electronics Engineering from The Islamia University of Bahawalpur and M.Sc. in Electrical Engineering from the University of Engineering and Technology (UET) Lahore, Pakistan, in 2007 and 2011 respectively. Currently he is a Ph.D. student at the Department of Electrical Power Engineering and Mechatronics, Tallinn University of Technology, Estonia.

His area of interest includes design, modelling and fault diagnostics of electrical machines. E-mail: biasad@ttu.ee

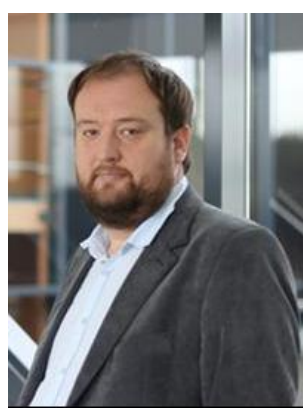

Toomas Vaimann received his B.Sc., M.Sc. and $\mathrm{Ph} . \mathrm{D}$. degrees in electrical engineering from Tallinn University of Technology, Estonia, in 2007,2009 and 2014 respectively. He is currently a senior researcher at Tallinn University of Technology, Department of Electrical Power Engineering and Mechatronics. He has been working in several companies as an electrical engineer. He is a member of IEEE, Estonian Society of Moritz Hermann Jacobi and Estonian Society for Electrical Power Engineering.

His main research interest is the diagnostics of electrical machines.

E-mail: Toomas.Vaimann@taltech.ee

ORCID iD: https://orcid.org/0000-0003-0481-5066 


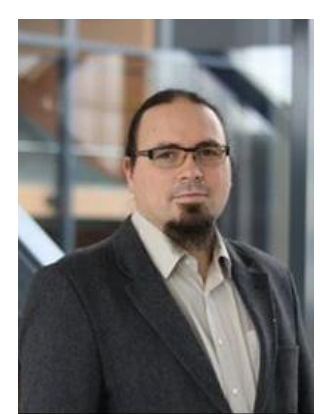

Ants Kallaste received his B.Sc., M.Sc. and $\mathrm{Ph} . \mathrm{D}$. degrees in electrical engineering from Tallinn University of Technology, Estonia, in 2004, 2006 and 2013 respectively. He is currently a senior researcher at Tallinn University of Technology, Department of Electrical Power Engineering and Mechatronics. He is holding the position of the Head of Electrical Machines Research Group. He is a member of IEEE and Estonian Society of Moritz Hermann Jacobi.

His main research interest is design of electrical machines.

E-mail: Ants.Kallaste@taltech.ee

ORCID iD: https://orcid.org/0000-0001-6126-1878

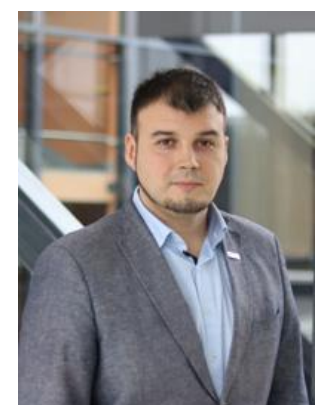

Anton Rassõlkin received Ph.D. degree in electric drives and power electronics from Tallinn University of Technology in 2014. His main research interests are in the field of electric drives and their control systems as well as in the fields of electrical machines and electric transportation. $\mathrm{He}$ works as a Research Scientist at the Department of Electrical Power Engineering and Mechatronics at Tallinn University of Technology, Department of Electrical Power Engineering and Mechatronics, Tallinn University of Technology, Ehitajate tee 5, 19086 Tallinn, Estonia.

E-mail: Anton.Rassolkin@taltech.ee

ORCID iD: https://orcid.org/0000-0001-8035-3970

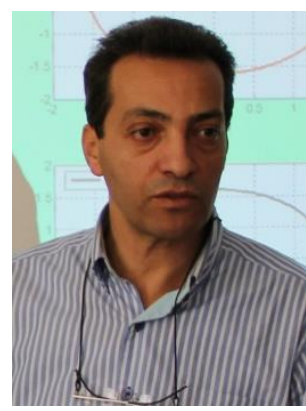

Anouar Belahcen received B.Sc. degree in physics from the University Sidi Mohamed Ben Abdellah, Fes, Morocco, in 1988 and M.Sc. (Tech.) and Doctor (Tech.) degrees from Helsinki University of Technology, Finland, in 1998, and 2004 , respectively.

$\mathrm{He}$ is the professor of electrical machines at Tallinn University of Technology, Estonia and the professor of Energy and Power at Aalto University, Finland.

His research interests are modelling of electrical machines, magnetic materials, coupled magnetic and mechanical problems and magnetostriction.

E-mail: Anouar.Belahcen@taltech.ee

ORCID iD: https://orcid.org/0000-0003-2154-8692

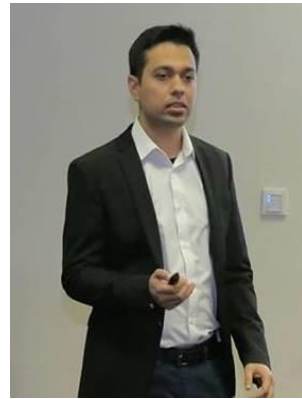

M. Naveed Iqbal was born in 1988 in Pakistan. He received his B.Sc. in Electronics Engineering in 2008 from Islamia University of Bahawalpur and M.Sc. degree from University of New South Wales, Australia. He is currently a doctoral student at Tallinn University of Technology. His area of interest includes energy consumption modelling and power quality.

Email:miqbal@ttu.ee 